\title{
Toughening mechanism and frontal process zone size of ceramics
}

\author{
Hideo AWAJI, ${ }^{\dagger}$ Yoshitaka NISHIMURA, ${ }^{*}$ Seong-Min CHOI, ${ }^{*}$ Yoshikazu TAKAHASHI, ${ }^{*}$ Tomoaki GOTO* \\ and Shinobu HASHIMOTO ${ }^{* *}$
}

Korea Fine Ceramics Center, Gangneung Sci. Park, Daejeondong, Gangneung 210-340 Korea

${ }^{*}$ Fuji Electric Device Tech., Co., Ltd., Tsukama, Matsumoto, Nagano 390-0821

**Nagoya Institute of Technology, Gokiso-cho, Showa-ku, Nagoya, Aichi 466-8555

\begin{abstract}
In order to improve the fracture toughness of intrinsically brittle ceramics, it is essential to expand the frontal process zone (FPZ) ahead of a crack tip. Nanocomposites proposed by Niihara utilize dislocations generated around the dispersed nanosized particles in matrix and expand the FPZ. In this paper, we discussed the toughening mechanism of ceramics using our experimental data on alumina-based nanocomposites, focusing on fundamental theories of fracture mechanics, such as Griffith-Irwin energy equilibrium and the local fracture criterion. We estimated the FPZ size using an indirect technique proposed recently, and clarified that the FPZ expansion toughening mechanism is achieved in nanocomposites by means of dislocation activities. The results revealed that ceramics with a larger FPZ size had higher fracture toughness and properly annealed nanocomposites had the largest FPZ size. The FPZ expansion mechanism in nanocomposites was considered that sessile dislocations generated around a crack tip in matrix, served as nano-crack nuclei, and hence expanded the FPZ size. It is clarified that the critical local stress is the strength of an infinite plate with no crack, and must be the true strength with no size effect. The fracture toughness, the critical local stress, and the FPZ size are the mutually dependent material properties, and the relation among them is clarified.
\end{abstract}

(02009 The Ceramic Society of Japan. All rights reserved.

Key-words : Nanocomposites, Alumina, Silver, Nickel, Toughening mechanism, Frontal process zone, Critical local stress

[Received November 4, 2008; Accepted March 17, 2009]

\section{Introduction}

Ceramic-based nanocomposites were originally proposed by Niihara and Hirai ${ }^{1)}$ in 1986 to overcome the inherent brittleness of ceramics using a chemical-vapor-deposition technique for the silicon nitride-titanium nitride system and silicon carbide with stacking faults. This idea was developed into a new materials design concept of ceramic-based nanocomposites by Niihara. ${ }^{2)}$ Since then, nanocomposites have been studied extensively because of their significantly improved mechanical properties, such as strength, fracture toughness, wear resistance, and creep resistance. $^{3)-6)}$

Recently, we proposed the strengthening and toughening mechanisms of ceramic-based nanocomposites on the basis of dislocation activities. ${ }^{7)}$ An intra-type nanostructure where the nano-sized particles are embedded within the matrix grains, induces a thermal expansion mismatch between the matrix and particles, and generates dislocations around the particles. The important point is only lattice defects such as dislocations can be generated around the nano-sized particles in ceramic grains, because these particles induce nano-scale residual stress distributions. Also, these dislocations in ceramics become sessile dislocations at room temperature and serve as nano-crack nuclei in highly stressed field, e.g., at a crack tip. The dislocations, therefore, expand the frontal process zone (FPZ) size and consequently improve the fracture toughness.

This concept is based on the experimental results of dislocation activities in $\alpha$-alumina single crystal measured by Lagerlöf et al., ${ }^{8)}$ theoretical estimation of the FPZ size in ceramics pre-

Corresponding author: H. Awaji; E-mail: hideo.awaji@gmail.com sented by Awaji et al.,9) and experimentally clarified annealing effects on alumina-based nanocomposites. ${ }^{6)}$ In order to improve the fracture toughness of intrinsically brittle ceramics, it is therefore essential to generate dislocations and expand the FPZ ahead of a crack tip.

The mechanisms of the FPZ expansion in ceramics are mainly based on dislocation activities, phase transformation in the FPZ, and pore-related microstructures. Nanocomposites utilize dislocations generated around the dispersed nano-sized particles in matrix. Partially stabilized zirconia expands the FPZ by means of stress-induced phase transformation around the crack tip. Ceramics with porous microstructure, however, have much lower strength and lower fracture toughness ${ }^{10)}$ in spite of having larger FPZ size than dense ceramics.

The relation between the FPZ size and the fracture toughness in brittle ceramics was discussed previously by us ${ }^{11)}$ for the case of mode II and combined mode I-II crack extensions, where the theory of Griffith's energy equilibrium was extended for kinked crack propagation under mode II and combined mode loadings, and the fracture energy rate was estimated from the areas of the FPZ under mode I and mode II loads. The results were used to estimate the ratio of mode I to mode II fracture toughness, and the estimated ratio agreed with experimental results.

In this paper, we discuss the toughening mechanism of polycrystalline alumina, focusing on the FPZ size. The FPZ expansion toughening mechanism will be clarified using linear elastic fracture mechanics (LEFM). Because ceramics have a very small FPZ size, LEFM is usually applicable to ceramics.

Although Irwin and Dugdale models ${ }^{12)}$ are used to estimate plastic zone size ahead of a crack tip, most of the ceramics don't generate dislocations at room temperature except in a compres- 
sive stress state. ${ }^{8)}$ These models, therefore, are not applicable to the ceramics. We use the concepts of Griffith-Irwin energy equilibrium and the local fracture criterion ${ }^{13)}$ for intrinsically brittle materials.

Ceramics with macroscopically laminated textures or long fiber-reinforced composites are potential materials to improve fracture toughness of ceramics. However, we will not discuss these composites, because there are some difficulties in applying LEFM and the local fracture criterion to those materials. The theory discussed here is only applicable to monolithic ceramics and ceramic-based composites with small FPZ size.

\section{Theory}

\subsection{Griffith-Irwin criterion}

Griffith's energy equilibrium is now called the maximum energy release rate theory, which constructs energy equilibrium between the maximum energy release rate and fracture energy rate at a crack tip. ${ }^{14)}$ If the crack length is sufficiently long compared with the FPZ size, LEFM is applicable to the energy equilibrium. In this case, the maximum energy release rate due to unit crack extension under mode I loading can be simply expressed using Irwin's stress intensity factor (SIF) as,

$$
G=\frac{K_{I}^{2}}{E^{\prime}},
$$

where $G$ denotes the maximum energy release rate, $K_{\mathrm{I}}$ is the SIF, and $E^{\prime}=E$ : plane stress state and $E^{\prime}=E /\left(1-v^{2}\right)$ : plane strain state, $E$ is Young's modulus, $v$ is Poisson ratio. Equation (1) indicates that the driving force for the crack extension, $G$, can be determined independent of the way of the FPZ formation, such as dislocations, micro-cracks, and lattice defects, as long as the FPZ size is sufficiently small.

Material resistance for crack extension per unit size, $R$, represents the energy consumed in the FPZ, which is expressed as,

$$
R=2 \gamma_{\mathrm{I}},
$$

where $\gamma_{\mathrm{I}}$ is the fracture energy per unit crack extension consumed in the FPZ formation. Then, Griffith-Irwin energy equilibrium at the beginning of the crack extension can be expressed from Eqs. (1) and (2) as

$$
\frac{K_{\mathrm{IC}}^{2}}{E^{\prime}}=2 \gamma_{\mathrm{I}},
$$

where $K_{\mathrm{IC}}$ represents the fracture toughness of the material.

Figure 1 shows the relation between the maximum energy

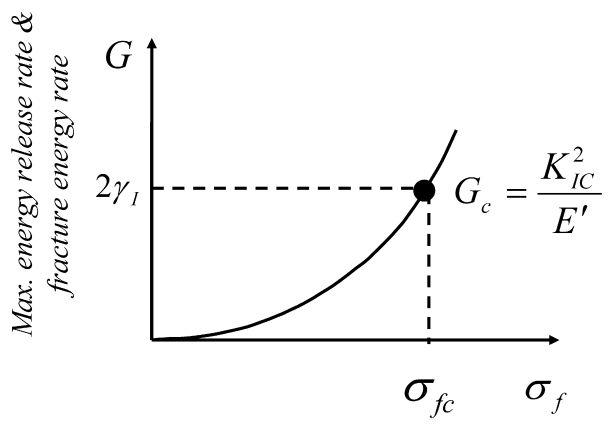

Remote stress

Fig. 1. Relation between the maximum energy release rate and the fracture energy rate, where horizontal axis indicates the remote stress on the specimen. release rate, $G$, and the remote stress on a specimen with a crack, $\sigma_{\text {f. }}$ It also shows the energy equilibrium between $G$ and $R$ at the crack extension, where $G_{\mathrm{c}}$ denotes the critical maximum energy release rate and $\sigma_{\mathrm{fc}}$ is the critical remote stress.

\subsection{Strength and fracture toughness}

Strength of brittle materials depends strongly on the weakest defect size in the materials considered. Therefore, the strength varies with the specimen size used, which is called "size effects." On the contrary, fracture toughness of ceramics is almost independent of the specimen size, because the fracture toughness is mainly determined by the fracture energy consumed in the FPZ formation at the crack tip.

If the weakest defect in the material can be replaced with a crack in an infinite plate shown in Fig. 2, and if the crack length is sufficiently long to apply LEFM, the following relation between the remote stress and the SIF is derived,

$$
K_{\mathrm{I}}=\sigma_{\mathrm{f}} \sqrt{\pi a_{\mathrm{e}}},
$$

where $a_{\mathrm{e}}$ is the half crack length in an infinite plate and $\sigma_{\mathrm{f}}$ is the remote stress on the plate. Then the relation between the strength and fracture toughness of the infinite plate with a crack is expressed under the critical stress state as follows:

$$
K_{\mathrm{IC}}=\sigma_{\mathrm{fc}} \sqrt{\pi a_{\mathrm{e}}},
$$

where $\sigma_{\mathrm{fc}}$ is the strength of the plate. Equation (5) indicates that the strength is a function of the crack length included in the material, because $K_{\mathrm{IC}}$ is a material constant as shown in Eq. (3). Therefore, if we reduce the weakest defect size by means of microstructural refinement of the material, the strength of the material can be improved. Equation (5) is, however, only applicable to the long crack problem. The actual defect size in fine ceramics is not sufficiently large to apply LEFM in the materials, which will be discussed later.

Regarding the strength of ceramics, we must point out the fact that there are considerable residual stresses in polycrystalline ceramics after sintering, ${ }^{9}$ ) resulting from anisotropic thermal expansion and Young's modulus along the crystal axes, grain size inhomogeneity, and crystallographic misorientation across the grain boundaries. Because the residual stresses decrease the strength of materials considerably, it is necessary to estimate the residual stresses in crystals to clarify the inherent strength of materials. However, measurement of the residual stresses in such a small grain is almost impossible at the present. ${ }^{15)}$ 


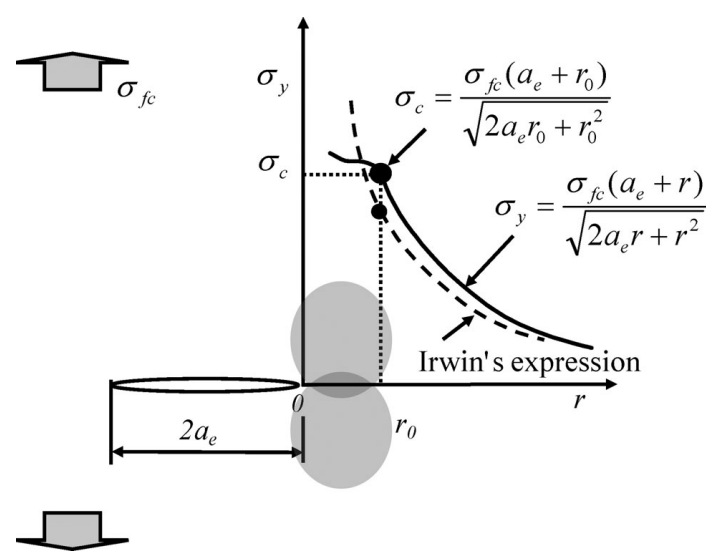

Fig. 3. Stress distribution ahead of a crack tip under the critical stress state, where the crack is not sufficiently long compared with the FPZ size.

\subsection{Stress distribution ahead of a crack tip}

For a crack in an infinite plate under mode I loading, the exact solution of the normal stress on the $r$-axis ahead of the crack tip is expressed as, ${ }^{14)}$

$$
\sigma_{\mathrm{y}}=\frac{\sigma_{\mathrm{f}}\left(a_{\mathrm{e}}+r\right)}{\sqrt{2 a_{\mathrm{e}} r+r^{2}}}=\sigma_{\mathrm{f}} F(r),
$$

where $\sigma_{\mathrm{y}}$ represents the normal stress, $r$ is the distance from the crack tip, and $F(r)$ is the non-dimensional stress distribution ahead of a crack tip.

The stress distribution in an infinite plate is shown in Fig. 3 for a short crack case, where the crack length is not sufficiently long compared with the FPZ size. In this case, the difference between the exact stress distribution shown by the solid curve and Irwin's expression shown by the dotted curve is considerably large at the FPZ size, $r_{0}$. Hence, we must use Eq. (6) to express the stress at $r_{0}$.

For a problem of a long crack in an infinite plate, the distribution of the normal stress along the $r$-axis under the critical state is expressed in the range $r_{0} \leq r \ll a_{\mathrm{e}}$, using Irwin's expression $^{14)}$ as,

$$
\sigma_{\mathrm{y}} \approx \frac{K_{\mathrm{IC}}}{\sqrt{2 \pi r}},
$$

In this case, the characteristic stress, $\sigma_{\mathrm{c}}$, at $r_{0}$ is derived from Eq. (7) as follows:

$$
\sigma_{\mathrm{c}} \approx \frac{K_{\mathrm{IC}}}{\sqrt{2 \pi r_{0}}} .
$$

Equation (8) implies that $K_{\mathrm{IC}}, r_{0}$, and $\sigma_{\mathrm{c}}$ are mutually dependent material constants.

However, Irwin's expression is not always applicable to actual defects existing in materials. For fine ceramics, the weakest defect size is very small and is not sufficiently long compared with the FPZ size. When we concern the stress distribution around the crack tip, it is therefore necessary to clarify whether LEFM is applicable or not.

\subsection{Local fracture criterion}

The local fracture criterion ${ }^{13)}$ states that the crack will propagate when the stress at the characteristic distance from the crack tip reaches the critical local stress. Then, if the characteristic distance is equal to the critical FPZ size, we obtain the same equa-

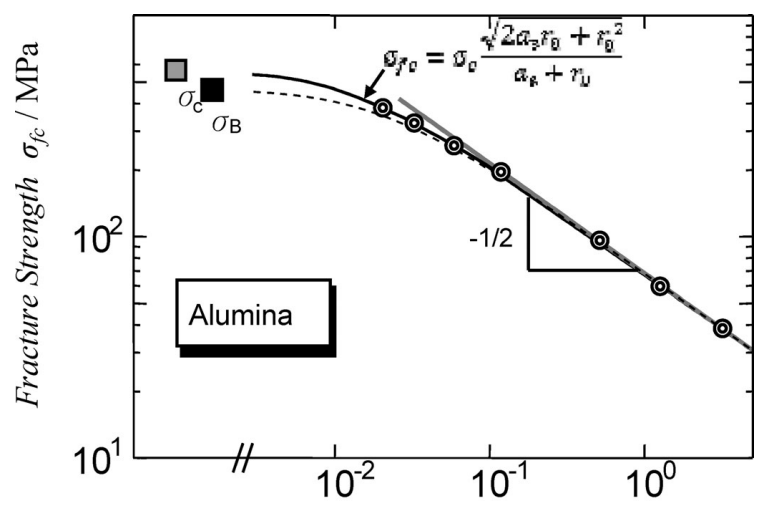

Equivalent Crack Length $a_{e} / \mathrm{mm}$

Fig. 4. Experimentally obtained results of the bending strength of specimens with and without a V-notch, the critical local stress, $\sigma_{\mathrm{c}}$, and the calculated strength of the infinite plate with a crack, $\sigma_{\mathrm{fc}}$, expressed in Eq. (10).

tion as Eq. (8) from the local fracture criterion, which means that for a long crack problem, global approach of Griffith-Irwin criterion and local approach of the local fracture criterion become identical at $r_{0}$.

For a short crack problem shown in Fig. 3, we must use Eq. (6) to calculate the critical local stress. The stress at $r_{0}$ in a critical state is expressed from Eq. (6) as,

$$
\sigma_{\mathrm{c}}=\sigma_{\mathrm{fc}} F\left(r_{0}\right) \text {. }
$$

Then the strength, $\sigma_{\mathrm{fc}}$, of the infinite plate with an arbitrary crack length is given by,

$$
\sigma_{\mathrm{fc}}=\sigma_{\mathrm{c}} \frac{\sqrt{2 a_{\mathrm{e}} r_{0}+r_{0}^{2}}}{a_{\mathrm{e}}+r_{0}} .
$$

If we take the limit as $a_{\mathrm{e}}$ goes to zero in Eq. (10), the following relation is derived,

$$
\lim _{a_{\mathrm{e}} \rightarrow 0} \sigma_{\mathrm{fc}} \rightarrow \sigma_{\mathrm{c}} .
$$

This indicates that $\sigma_{\mathrm{c}}$ has two significant meanings. One is that $\sigma_{\mathrm{c}}$ is the critical local stress ahead of the crack tip, and the other is that $\sigma_{\mathrm{c}}$ is the strength of an infinite plate with no crack, that is to say, $\sigma_{\mathrm{c}}$ is the strength with no size effect and must be one of the fundamental properties of the material.

Previously we described the experimental relation between the strength and notch depth ${ }^{16)}$ using the single edge V-notched beam (SEVNB) technique ${ }^{17}$ ) for polycrystalline alumina. JIS R 1601 type three-point bending test was performed for the specimens with various depths of a V-notch. The results are shown in Fig. 4, where the vertical axis indicates the bending strength of the specimen and horizontal axis is an equivalent crack length. Both axes are in log scales. The equivalent crack length is the crack length in an infinite plate with the same SIF as the edge-cracked bending specimen. In Fig. 4, the double circles indicate the average strength of the specimens with various depths of the V-notch, the solid square is the average bending strength of the specimens without a notch, $\sigma_{\mathrm{B}}$, and the gray square indicates the estimated critical local stress, $\sigma_{\mathrm{c}}$. The solid curve represents the strength shown in Eq. (10) using the estimated critical local stress, $\sigma_{\mathrm{c}}$, the FPZ size, $r_{0}$, and the equivalent crack length, $a_{\mathrm{e}}$. The gray straight line with $-1 / 2$ gradient is the line calculated by the $K_{\mathrm{IC}}$ value, which indicates when the equivalent crack length is longer than $100 \mu \mathrm{m}, \mathrm{LEFM}$ is applicable to the material. The technique 


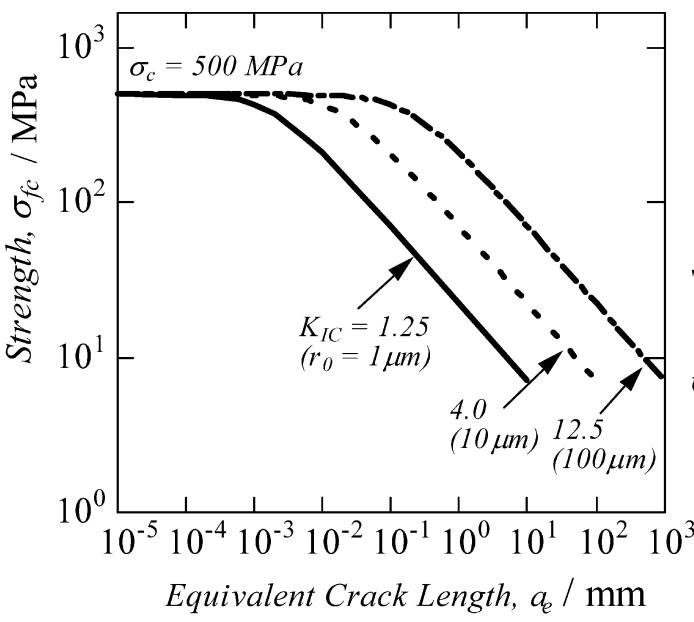

(A)

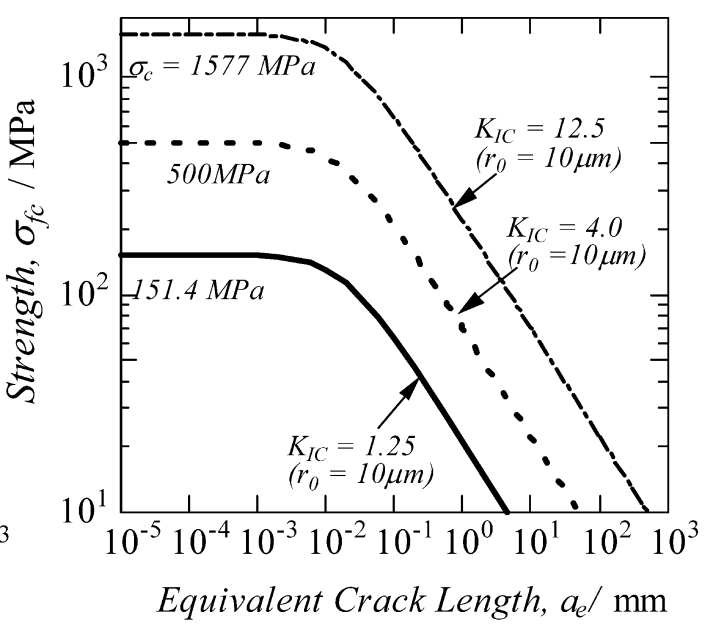

(B)

Fig. 5. Simulated relation between the strength of the specimen with a crack and the equivalent crack length. In $(\mathrm{A}), \sigma_{\mathrm{c}}=500 \mathrm{MPa}$, and in $(\mathrm{B}), r_{0}=10 \mu \mathrm{m}$.

for estimating both the critical local stress and the FPZ size are explained elsewhere. ${ }^{9}$

The results revealed that the experimental data of the notched specimens is on the curve of the strength, $\sigma_{\mathrm{fc}}$, and the curve converges on the critical local stress, $\sigma_{\mathrm{c}}$, which means that the local fracture criterion is valid for not only a long crack problem but also a quite short crack problem. Also, it is known that the critical local stress and the bending strength are different. The value of $\sigma_{\mathrm{c}}$ is independent of the specimen size, while $\sigma_{\mathrm{B}}$ has a size effect. Therefore, $\sigma_{\mathrm{c}}$ represents the "true strength" of the material without a size effect.

The relations among the strength, the equivalent crack length, and the fracture toughness are simulated in Fig. 5, where we consider two typical cases. In Fig. 5(A), $\sigma_{\mathrm{c}}$ is kept under $500 \mathrm{MPa}$ and $r_{0}$ is changed to 1,10 , and $100 \mu \mathrm{m}$, whereas in Fig. 5(B), $r_{0}$ is kept in $10 \mu \mathrm{m}$ and $\sigma_{\mathrm{c}}$ is changed to $151.4,500$, and $1577 \mathrm{MPa}$. The solid curves in both (A) and (B) indicate the strength of the material with $K_{\mathrm{IC}}=1.25 \mathrm{MPam}^{1 / 2}$, the dotted curves; $K_{\mathrm{IC}}=4.0$ $\mathrm{MPam}^{1 / 2}$, and dot-dashed curves; $K_{\mathrm{IC}}=12.5 \mathrm{MPam}^{1 / 2}$. These figures suggest that the materials with both larger FPZ size and higher critical local stress show higher fracture toughness. It is also confirmed that the fracture toughness, the critical local stress, and the FPZ size are fundamental material properties.

\subsection{FPZ size}

Because the technique for estimating the FPZ size is explained elsewhere, ${ }^{9)}$ the summary is only shown here. Equation (8) and following formula are used to estimate the critical local stress, $\sigma_{\mathrm{c}}$, and the FPZ size, $r_{0}$,

$$
\frac{\sigma_{\mathrm{c}}}{\sigma_{\mathrm{B}}} \approx\left\{\frac{V_{\mathrm{B}}}{V_{\mathrm{FPZ}}}\right\}^{1 / m},
$$

where, $V_{\mathrm{B}}$ and $V_{\mathrm{FPZ}}$ represent effective volumes of the three-point bending specimen and critical FPZ, respectively and $m$ is a shape factor of Weibull distribution. Equation (12) indicates the relation between the critical local stress and the bending strength derived using Weibull statistics. ${ }^{9)}$

From Eqs. (8) and (12), the following relation is derived.

$$
K_{\mathrm{IC}} \propto \sigma_{\mathrm{B}} \cdot r_{0}^{1 / 2} .
$$

This equation indicates that the fracture toughness is propor- tional to the bending strength and square root of the FPZ size. This relation will be expressed experimentally in the following section.

Since metallic materials deform plastically above the yielding stress, there is an extended plastic zone ahead of the crack tip. The plastic zone size was analyzed by Irwin and Dugdale in the case that the plasticity is confined to a small region surrounding the crack tip. ${ }^{12)}$ A plastic zone size of Irwin's result, $r_{y}$, is expressed as,

$$
r_{\mathrm{y}}=\frac{1}{\pi}\left(\frac{K_{\mathrm{IC}}}{\sigma_{\mathrm{ys}}}\right)^{2},
$$

and the Dugdale's plastic zone size, $r_{\mathrm{y}}^{*}$, is

$$
r_{\mathrm{y}}^{*}=\frac{\pi}{\varepsilon}\left(\frac{K_{\mathrm{IC}}}{\sigma_{\mathrm{ys}}}\right)^{2},
$$

where $\sigma_{\text {ys }}$ represents the yield stress of the material. These results were derived for the state of plane stress.

Although the FPZ size in ceramics will not be formed by dislocations at room temperature, we apply Eqs. (14) and (15) to calculate FPZ size in ceramics by assuming $\sigma_{\mathrm{ys}}=\sigma_{\mathrm{c}}$. From Eqs. (8), (14), and (15), the relation between the FPZ size, and Irwin's and Dugdale's plastic zone sizes is derived as,

$$
r_{0}=\frac{1}{2 \pi}\left(\frac{K_{\mathrm{IC}}}{\sigma_{\mathrm{c}}}\right)^{2}=2 r_{\mathrm{y}}=\frac{1}{2.46} r_{\mathrm{y}}^{*} .
$$

In the FPZ calculation, we disregarded the non-linear stress distribution in the FPZ, because dislocation movement is difficult in the FPZ in ceramics, whereas Irwin's and Dugdale's plastic zones are derived on the assumption that the stresses become a constant above the yielding stress.

\section{Results and discussion}

In order to improve the fracture toughness of alumina ceramics, it is essential to fabricate nanocomposites with an intra-type nanostructure, where the second phase nano-particles are embedded within the alumina matrix, generate dislocations around the particles at high temperature due to thermal expansion mismatch between the matrix and particles. ${ }^{6)}$ These dislocations become sessile dislocations at room temperature, serve as nano-crack nuclei in the FPZ, expand the FPZ size, and conse- 
quently enhance the fracture toughness of ceramics. Ceramicbased nanocomposites are fabricated using high-speed sintering techniques, such as hot pressing or pulse electric current sintering (PECS) to avoid segregation of the second-phase particles to the matrix boundaries.

The soaking method ${ }^{18), 20)}$ was developed as a new technique for fabricating intra-type nanocomposites using $\gamma$-alumina powder (AKP-G015, Sumitomo Chemical Co.) with much nanoporosity. The $\gamma$-alumina powder is soaked in a metal nitrate solution in vacuum, filtered and dried, followed by calcination to get metal oxide particles in the pores of the $\gamma$-alumina powder. The calcinated powder is then reduced in hydrogen atmosphere to obtain metallic nano-grains in the $\gamma$-alumina agglomerates. Upon sintering, we obtain intra-type nano-structured alumina-metal nanocomposites.

In this paper, we compared the three kinds of materials named "monolithic alumina," "as-sintered nanocomposites," and "annealed nanocomposites." The monolithic alumina was sintered using the PECS technique for $\alpha$-alumina powder (AKP-53, Sumitomo Chemical Co.) under the same condition as the nanocomposites for comparison. The as-sintered nanocomposites were sintered under the conditions explained later for each material. These conditions yielded high density with the highest strength and fracture toughness for the alumina-silver and alumina-nickel systems, presented previously. ${ }^{19), 20)}$ The annealed nanocomposites are the material annealed properly after sintering to disperse dislocations generated around the second-phase particles into the alumina matrix grains.

Three-point bending specimens used were $2 \times 2 \times 10 \mathrm{~mm}$ in size $($ span $=8 \mathrm{~mm})$, which was smaller than the specimen defined in JIS R 1607 because of small capacity of our PECS equipment (SPS-515S, Sumitomo Coal Mining Co., Ltd.). The fracture toughness was measured by the SEVNB technique, ${ }^{17)}$ using the specimens with a sharp V-shaped notch.

\subsection{Alumina-silver nanocomposites}

Because the experimental procedure of the soaking method for alumina-silver nanocomposites was reported elsewhere, ${ }^{19), 21)}$ we describe it briefly here. Using the commercially available $\gamma$ alumina powder (AKP-G015) and silver sulfate $\left(\mathrm{Ag}_{2} \mathrm{SO}_{4}\right.$, Kishida Chemistry Co., Ltd.), $\gamma$-alumina powder containing nano-sized silver was prepared. Also, to improve the sinterability of the specimens, we added 10 mass $\% \alpha$-alumina powder (AKP53) as a seed.

The specimens were sintered using the PECS technique at $1350^{\circ} \mathrm{C}$ for $5 \mathrm{~min}$ under $30 \mathrm{MPa}$ in vacuum. The volume fraction of the silver particles was approximately $1 \mathrm{vol} \%$. The specimens were then annealed for $5 \mathrm{~min}$ at $800^{\circ} \mathrm{C}$ in argon atmosphere.

The experimental results are summarized in Table 1, where the average values of the measured strength and fracture toughness, and calculated values of the FPZ size, the critical local stress, the values of $\sigma_{\mathrm{B}} \cdot r_{0}{ }^{1 / 2}$, and the Dugdale's plastic zone size obtained from Eq. (15) are shown for the as-sintered and annealed nanocomposites. Table 1 indicates that the annealed nanocomposites have higher values of the strength and fracture toughness, and larger FPZ size than the as-sintered nanocomposites, but the difference is relatively small. One reason of this minor improvement depends on the small volume fraction of silver particles included in the matrix (approximately 1\%). The other reason will be explained in Discussion.

It is recognized in Table 1 that both the FPZ size and the Dugdale's plastic zone size are very small, and almost the same critical local stresses are found in the as-sintered and annealed nanocomposites.

The scanning electron microscope (SEM) observations of the fracture surfaces of the bending specimens of the alumina-silver nanocomposites were almost transgranular fracture, whereas monolithic alumina shows intergranular fracture. ${ }^{18)}$ The transgranular fracture mode indicates that the residual stresses in alumina grains were released by the generation of dislocations and hence the strength was improved. Also dislocations are expected to expand the FPZ size and fracture toughness is enhanced accordingly.

\subsection{Alumina-Ni nanocomposites}

Using the commercially available $\gamma$-alumina powder (AKPG015) and nickel nitrate solution (Osaka Chemical Co., Ltd.), $\gamma$ alumina powder containing nano-sized nickel was prepared. To improve the sinterability of the specimens, we added 10 mass $\%$ $\alpha$-alumina powder (TM-D, Taimei Chemical Co.) as a seed and 0.25 mass $\% \mathrm{MgO}$ as a sintering additive in this case. The mixtures were sintered by the PECS method at $1350^{\circ} \mathrm{C}$ under 30 $\mathrm{MPa}$ in vacuum for $5 \mathrm{~min}$. The volume fraction of nickel particles was about $3 \%$. To disperse the dislocations generated around the nano-particles into alumina grains, the sintered specimens were annealed at $800^{\circ} \mathrm{C}$ for $5 \mathrm{~min}$. Further details are explained in Ref. 20.

The SEM observations of the fracture surfaces of the bending specimens of the alumina-nickel nanocomposites were almost transgranular mode whereas monolithic alumina showed intergranular mode. ${ }^{20)}$

The experimental results are summarized in Table 2, where

Table 1. Summary of the As-sintered and Annealed Alumina-Ag Nanocomposites

\begin{tabular}{ccc}
\hline & $\begin{array}{c}\text { As-sintered } \\
\text { alumina-Ag } \\
\text { nanocomposites }\end{array}$ & $\begin{array}{c}\text { Annealed } \\
\text { alumina-Ag } \\
\text { nanocomposites }\end{array}$ \\
\hline Strength $\sigma_{\mathrm{B}} / \mathrm{MPa}$ & 780 & 810 \\
Fracture toughness $K_{\mathrm{IC}} / \mathrm{MPam}^{1 / 2}$ & 3.6 & 4.21 \\
FPZ size $r_{0} / \mu \mathrm{m}$ & 1.56 & 2.11 \\
Critical local stress $\sigma_{\mathrm{c}} / \mathrm{MPa}$ & 1150 & 1157 \\
$\sigma_{\mathrm{B}} \cdot r_{0}^{1 / 2} / \mathrm{MPam}^{1 / 2}$ & 0.97 & 1.18 \\
Plastic zone size $r_{\mathrm{y}}^{*} / \mu \mathrm{m}$ & 3.9 & 5.2 \\
\hline
\end{tabular}

Table 2. Summary of the Monolithic Alumina, As-sintered and Annealed Alumina-Ni Nanocomposites

\begin{tabular}{|c|c|c|c|c|}
\hline & \multicolumn{2}{|c|}{ Monolithic alumina } & \multirow{2}{*}{$\begin{array}{c}\text { As-sintered } \\
\text { alumina-Ni } \\
\text { nanocomposites }\end{array}$} & \multirow{2}{*}{$\begin{array}{c}\text { Annealed } \\
\text { alumina-Ni } \\
\text { nanocomposites }\end{array}$} \\
\hline & original & modified* & & \\
\hline $\begin{array}{l}\text { Strength } \\
\sigma_{\mathrm{B}} / \mathrm{MPa}\end{array}$ & 521 & 781 & 877 & 888 \\
\hline $\begin{array}{c}\text { Fracture toughness } \\
K_{\mathrm{IC}} / \mathrm{MPam}^{1 / 2}\end{array}$ & 3.78 & 3.78 & 5.49 & 7.59 \\
\hline $\begin{array}{l}\text { FPZ size } \\
r_{0} / \mu \mathrm{m}\end{array}$ & 4.86 & 1.76 & 3.36 & 7.31 \\
\hline $\begin{array}{c}\text { Critical local stress } \\
\sigma_{\mathrm{c}} / \mathrm{MPa}\end{array}$ & 684 & 1140 & 1190 & 1120 \\
\hline$\sigma_{\mathrm{B}} \cdot r_{0}^{1 / 2} / \mathrm{MPam}^{1 / 2}$ & 1.14 & 1.04 & 1.61 & 2.4 \\
\hline $\begin{array}{c}\text { Plastic zone size } \\
r_{\mathrm{y}}^{*} / \mu \mathrm{m}\end{array}$ & 12 & 4.3 & 8.4 & 18 \\
\hline
\end{tabular}

*The strength declined by the residual stresses was assumed to be $260 \mathrm{MPa}$. 


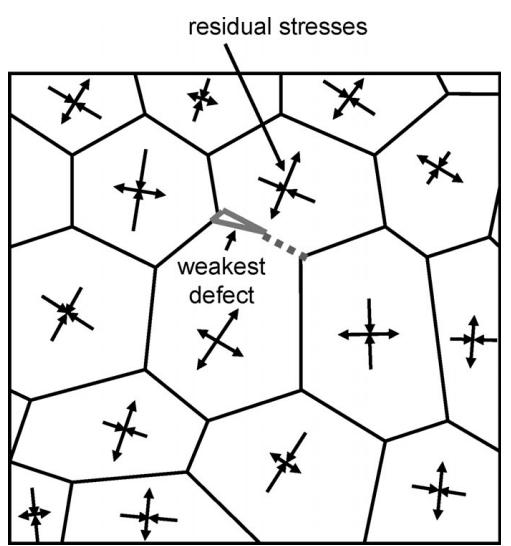

Fig. 6. Residual stresses in polycrystalline ceramics and the weakest defect, which describes that tensile residual stresses around the weakest defect reduce the strength substantially.

the average values of the measured strength and fracture toughness, and calculated values of the FPZ size, the critical local stress, the values of $\sigma_{\mathrm{B}} \cdot r_{0}{ }^{1 / 2}$, and the Dugdale's plastic zone size are shown for monolithic alumina, as-sintered nanocomposites, and annealed nanocomposites. In the column of the monolithic alumina, "original" means the experimentally obtained data without modification, and "modified" is the modified data taking account of residual stresses where the strength declined by the residual stresses was assumed to be $260 \mathrm{MPa}$. In other words, we thought that the inherent strength of the monolithic alumina without residual stresses should be $260 \mathrm{MPa}$ higher than the experimentally obtained data. ${ }^{9)}$

As explained in Fig. 6 schematically, monolithic alumina usually has residual stresses in each grain after sintering, and these residual stresses are in a self-equilibrium state in the specimen. Therefore, if there are tensile residual stresses around the weakest defect, as shown in Fig. 6, the strength will be reduced by the residual stresses.

Table 2 reveals that both the as-sintered and annealed nanocomposites have improved values of the strength, fracture toughness, and FPZ size. The annealed nanocomposites shows the highest strength, the highest fracture toughness, and the largest FPZ size, which indicates that proper annealing disperses dislocations in the matrix grains, increases the FPZ size, and results in the highest fracture toughness. The critical local stress is almost constant excluding the "original" data of monolithic alumina, despite the fact that the strengths show relatively large differences, which indicates that the critical local stress must be independent of the defect size existing in the materials.

\subsection{Discussions}

We will discuss the relatively small improvement in strength and fracture toughness of the alumina-silver nanocomposites, whereas the alumina-nickel nanocomposites have achieved high strength with high fracture toughness. Table 3 shows the thermal expansion coefficients and Young's moduli of alumina, nickel, and silver materials. Even though silver has higher thermal expansion coefficient, alumina-silver nanocomposites shows smaller improvement than alumina-nickel nanocomposites, as shown in Tables 1 and 2.

Simple solution of the residual stresses around a spherical second-phase particle in an infinite body was analyzed by Weyl ${ }^{22}$ and Selsing, ${ }^{23)}$ which is expressed as follows,

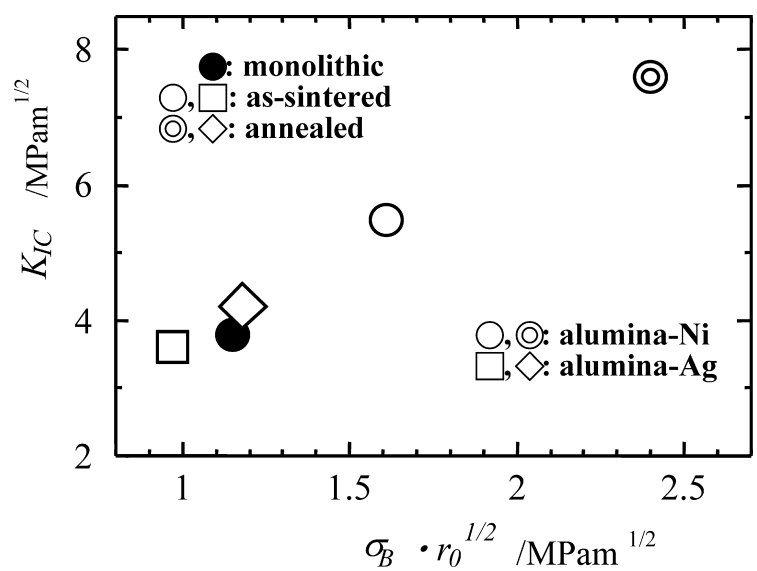

Fig. 7. Relation between the fracture toughness and $\sigma_{\mathrm{B}} \cdot r_{0}{ }^{1 / 2}$ for monolithic alumina, alumina-Ag nanocomposites, and alumina-Ni nanocomposites.

Table 3. Residual Stresses on the Sphere-matrix Boundary in an Infinite Body, where the Sphere is Ag or Ni and the Matrix is Alumina

\begin{tabular}{lccccc}
\hline $\begin{array}{c}\text { Thermal } \\
\text { expansion } \\
\text { coefficient of } \\
\text { matrix } \\
a_{\mathrm{m}}{ }^{* 1} \\
/ 10^{-6} \mathrm{~K}^{-1}\end{array}$ & $\begin{array}{c}\text { Thermal } \\
\text { expansion } \\
\text { coefficient of } \\
\text { particles } \\
a_{\mathrm{p}}{ }^{* 2} \\
/ 10^{-6} \mathrm{~K}^{-1}\end{array}$ & $\begin{array}{c}\text { Young's } \\
\text { modulus of } \\
\text { matrix } \\
E_{\mathrm{m}} \\
/ \mathrm{GPa}\end{array}$ & $\begin{array}{c}\text { Young's } \\
\text { modulus of } \\
\text { particles } \\
E_{\mathrm{p}} \\
/ \mathrm{GPa}\end{array}$ & $\begin{array}{c}\text { Hoop stress } \\
\text { on the matrix- } \\
\text { particle } \\
\text { boundary } \\
\sigma_{\theta} \\
/ \mathrm{MPa}\end{array}$ \\
\hline Alumina-Ni & 6.9 & 13.4 & 382 & 200 & 515 \\
Alumina-AG & 6.9 & 18.9 & 382 & 83 & 448
\end{tabular}

${ }^{{ }^{1} 1}$ : From catalogue of Pacific Rundum, ${ }^{{ }^{2}}$ : http//home.hiroshima-u.ac.jp/er/index.html

$$
\sigma_{\theta}=\frac{P}{2} \frac{b^{3}}{r^{3}}, \quad P=\frac{-\left(\alpha_{\mathrm{p}}-\alpha_{\mathrm{m}}\right) \theta_{0}}{\frac{1+v_{\mathrm{m}}}{2 E_{\mathrm{m}}}+\frac{1-2 v_{\mathrm{p}}}{E_{\mathrm{p}}}},
$$

where $\sigma_{\theta}$ represents the hoop stress around the sphere, $b$ is the radius of the sphere, $r$ is the distance from the center of the sphere, $\alpha$ is the thermal expansion coefficient, suffix $p$ denotes properties of the sphere, suffix $m$ represents properties of the matrix, and $\theta_{0}$ is the suffered temperature difference during sintering.

If we assume $v_{\mathrm{p}}=v_{\mathrm{m}}=0$ in Eq. (17) for simplicity, the stress on $r=b$ (particle-matrix boundary) is expressed as

$$
\sigma_{\theta}=-\left(\alpha_{\mathrm{p}}-\alpha_{\mathrm{m}}\right) \theta_{0} \frac{E_{\mathrm{m}} E_{\mathrm{p}}}{2 E_{\mathrm{m}}+E_{\mathrm{p}}}
$$

Table 3 shows the calculated residual stresses of alumina-nickel and alumina-silver systems for $\theta_{0}=1000 \mathrm{~K}$. It is recognized that there is large residual stress on the particle-matrix boundary, and even though silver has the larger value of $\alpha_{\mathrm{p}}$ than nickel, smaller residual stress is generated because of its small Young's modulus. In order to generate higher residual stresses, therefore, both larger difference of thermal expansion coefficient between the particle and matrix, and higher Young's moduli of both particle and matrix are needed.

Figure 7 shows the relation between the fracture toughness and the product of the bending strength and square root of the FPZ size, $\sigma_{\mathrm{B}} \cdot r_{0}{ }^{1 / 2}$, for alumina-silver nanocomposites and alumina-nickel nanocomposites. There is almost a linear relation between them as shown in Eq. (13), and from theoretical point of view, there is no trade-off relation between the strength and 
fracture toughness. It is also recognized that to improve the fracture toughness of materials, both higher strength and larger FPZ size are needed.

The strengthening and toughening mechanisms in as-sintered and annealed alumina-based nanocomposites are summarized as follows. In monolithic alumina, tensile residual stresses around the weakest defect substantially decrease the inherent strength. The strength of as-sintered nanocomposites is improved markedly by creation of dislocations and by reduction of the residual stresses in alumina grains. However, the FPZ size in as-sintered nanocomposites does not change substantially due to small contribution of dislocations to expand the FPZ. Upon annealing, dislocations are dispersed in the matrix grains and the fracture toughness of the annealed nanocomposites is significantly improved due to enlargement of the FPZ size. ${ }^{9)}$

\section{Conclusions}

In order to improve the fracture toughness of ceramics, the frontal process zone (FPZ) expansion mechanism in aluminabased nanocomposites was discussed, focusing on fundamental theories of fracture mechanics, such as Griffith-Irwin energy equilibrium and the local fracture criterion. The FPZ sizes in ceramics were estimated using the indirect technique presented previously to clarify the FPZ expansion mechanism.

Using the soaking method for fabricating an intra-type nanostructure, alumina-silver and alumina-nickel nanocomposites were produced, which showed large FPZ sizes after proper annealing. The results indicated that dislocations dispersed within alumina grains expanded the FPZ size and hence improved the fracture toughness. Also, it was confirmed that both the strength and the FPZ size must be increased to improve the fracture toughness of ceramics.

The local fracture criterion was applicable to ceramics not only in the case of long cracks but also in the case of short cracks. The theory produced the concept of the critical local stress, which is the strength of an infinite plate with no crack and the strength with no size effect, namely "the true strength". The relation among the fracture toughness, the critical local stress, and the FPZ size was shown, where all of these values are the fundamental material properties and mutually dependent.

\section{References}

1) K. Niihara and T. Hirai, Ceramics Japan, 21, 598-602 (1986) [in Japanese].

2) K. Niihara, J. Ceram. Soc. Japan, 99, 974-982 (1991).

3) A. Nakahira and K. Niihara, J. Ceram. Soc. Japan, 100, 448453 (1992) [in Japanese].

4) M. Nawa, T. Sekino and K. Niihara, J. Mater. Sci., 29, 31853192 (1994).

5) R. W. Davidge, R. J. Brook, F. Ca, Mbier, M. Poorteman, A. Leriche, D. O'Sullivan, S. Hampshire and T. Kennedy, Brit. Ceram. Trans., 96, 121-127 (1997).

6) S.-M. Choi and H. Awaji, Sci. \& Tech. of Advanced Mater., 6, 2-10 (2005).

7) H. Awaji, S.-M. Choi and E. Yagi, Mech. Mater., 34, 411-422 (2002).

8) K. P. D. Lagerlöf, A. H. Heuer, J. Castaing, J. P. Rivière and T. E. Mitchell, J. Am. Ceram. Soc., 77, 385-397 (1994).

9) H. Awaji, T. Matsunaga and S.-M. Choi, Materials Trans., 47, 1532-1539 (2006).

10) H. Awaji, C.-H. Chen and N. Kishi, Key Engineering Materials, Vols. 317-318, 281-284 (2006).

11) H. Awaji and T. Kato, Materials Trans., JIM, 40, 972-979 (1999).

12) M. Janssen, J. Zuidema and R. Wanhill, Fracture Mechanics, second ed., Spon Press, London (2002).

13) J. Besson ed., Local Approach to Fracture, Les Presses de l'École des Mines, Paris (2004).

14) H. Awaji, "Strength of Ceramic Materials," Corona Publ., Tokyo (2001) [in Japanese].

15) V. R. Vedula, S. J. Glass, D. M. Saylor, G. S. Rohrer, W. C. Carter, S. A. Langer and E. R. Fuller Jr., J. Am. Ceram. Soc., 84, 2947-2954 (2001).

16) H. Awaji, S.-M. Choi and D. D. Jayaseelan, J. Ceram. Soc. Japan, 109, 591-595 (2001).

17) H. Awaji, T. Watanabe, T. Yamada, Y. Sakaida, H. Tamiya and H. Nakagawa, Trans. Japan Soc. Mech. Engng., 56A, 1148-1153 (1990)

18) T. Matsunaga, U. Leela-Adisorn, Y. Kobayashi, S.-M. Choi and H. Awaji, J. Ceram. Soc. Japan, 113, 123-125 (2005) [in Japanese].

19) S.-H. Cheon, I.-S. Han and S.-K. Woo, J. Korean Ceram. Soc., 44, 343-348 (2007).

20) U. Leela-Adisorn, T. Matsunaga, Y. Kobayashi, S.-M. Choi and H. Awaji, Ceram. Int., 31, 803-809 (2005).

21) S.-H. Cheon, I.-S. Han and H. Awaji, J. Korean Ceram. Soc., 44, 208-213 (2007).

22) V. D. Weyl, Ber. Deut. Keram. Ges., 36, 319-324 (1959).

23) J. Selsing, J. Am. Ceram. Soc., 44, 419-419 (1961). 